\title{
MODELLING OF THE RELATION BETWEEN SUSTAINABLE DEVELOPMENT AND TIME ALLOCATION IN BSR COUNTRIES
}

Marta Hozer-Koćmiel, Ph.D.

University of Szczecin

Faculty of Economics and Management

Department of Statistics

Mickiewicza 64/66, 71-101 Szczecin, Poland

e-mail:mhk@wneiz.pl

Received 21 May 2014, Accepted 15 December 2014

\begin{abstract}
The aim of the article is to propose a simple Taxonomic Measure of Sustainable Development and to measure its relation with the time allocation. The research follows the scheme: i) the construction of the TMSD; ii) the regression analysis of the TMSD and time allocation variables; iii) the comparative analysis of the TMSD in 2004 and 2012 followed by the interpretation of the results.

The authors formulated the thesis about the relation between the level of sustainable development and the time allocation. The research shows that the more equal time allocation between men and women, the more sustainably developed the economy. This is probably because women live in a more sustainable way than men $^{1}$.

Also, the measure illustrates well how strongly differentiated the BSR countries are in terms of sustainable development. The most favourable situation was observed in Scandinavian countries and Norway. In most of the countries the level of sustainable development rose over the time of observation.
\end{abstract}

Keywords: sustainable development, TMSD Taxonomic Measure of Sustainable Development, time allocation, Baltic Sea Region.

JEL classification: F63, R11, Z13. 


\section{Introduction}

Studies which aim at quantifying the relationship between economic growth and gender equality show a strong and positive correlation between the two dimensions ${ }^{2}$. However, the way the GDP is calculated is subject to serious criticism pointing out that, among others, it ignores goods and services which are provided outside the market, such as household production and work, and misses and/or miscalculates some costs, such as environmental pollution or treating speculative bubbles (like those on financial and real estate markets) as the GDP increase. New measures of progress are still under discussion but clearly the thinking is along the concept of the HDI - Human Development Index, introduced by the UNDP, which incorporates not only the GDP per capita but also life expectancy and the level of education ${ }^{3}$.

The results of studies on the relation between the economic growth and gender equality have made the authors believe that it is necessary to take a broader view on the subject of their interest and to include the category of Sustainable Development into their considerations as it is the area that meets social, economic and environmental needs of present and future generations. The authors propose a simple Taxonomic Measure of Sustainable Development and measure its relationship with time allocation in the BSR countries. The fact that the time allocation, or time use budgets, has been included in their considerations meets the requirements of the Commission's postulate on the Measurement of Economic Performance and Social Progress ${ }^{4}$.

\section{Review of Literature}

There are few publications dealing with the relationship between development and gender equality and the discussion is usually limited to the micro-level, whereas the macroeconomic issues have not been tackled until recently ${ }^{5}$. What is more, the developing and the developed countries cannot be compared in terms of both development and time allocation ${ }^{6}$.

The relation under this study is described as a 'two-way street' since economic development has a considerable effect on gender equality and gender equality affects growth ${ }^{7}$. This opinion has been a starting point for considerations about the nature of this connection. In the reference literature authors mention its three types: casual connections, intentional connections and the connections of coexistence ${ }^{8}$. The term 'two-way street' and the empirical analyses of the examined relationship that ignore time delay indicate that we are dealing with the association of coexistence. Thereby the reason for this particular shape of the relationship should be searched for somewhere else. 
The global crisis of the last decade apparently worsened the economic situation in the BSR countries which saw decrease in production volume, salaries, employment, income, consumption and investment. The GDP growth rate went lower in wealthy countries that in the worse off countries after economic transformation. Despite the fact that the growth rates quickly recovered to its pre-crisis values, the quality of life of some population groups in Europe has evidently deteriorated ${ }^{9}$. The quantitative analyses in this field, with a special focus on Gross value added, were made by Lis $^{10}$.

In many regions women's economic situation is hard, due to their disadvantageous position on the labour market, lower salaries and incomes as well as their stronger dependence on social protection. At the time of crisis the situation gets even harder - this is why women's position on the labour market is often described as "last in - first out". This means that they less likely than men to find a good job and more likely to lose $i^{11}{ }^{11}$ Similar situation was observed in the countries of Central and Eastern Europe during the transition process of the 1990s when sharp decline in the GDP took place resulting in job losses and cuts in social protection.

Research on links between gender, economic growth and development has proven that power of the mutual impact of these categories can differ significantly depending on the type of growth and key driving factors such as exports ${ }^{12}$.

In the majority of the Baltic Sea Region countries the necessity to increase female participation rate in employment is strongly emphasized by both economists and politicians. It is generally believed that it is the best way to reduce a growing gap in labour force due to ageing (except migration). Increased women's market activity means more effective allocation of human resources, better use of people's talents - both women and men, the consequence of which is a positive effect on economic growth. Gender equality was thus described as "smart economics"13.

When it comes to the literature about the time allocation it has to be admitted that it often relates to equality issues ${ }^{14}$.

A significant part of housework are activities performed on behalf of other adults in the family. These chores have their economic value, even though they are not taken into consideration in central national accounts. There have been attempts to change this approach by promoting the concept of satellite accounts ${ }^{15}$, the latter being complementary to the central accounts that focus on a ,certain field or aspects of economic and social life e.g. unpaid household work in the context of national accounts"16.

In order to reach the desired level of men's and women's participation in economy their market and non-market activity must be balanced - their paid and unpaid work in particular. 
" $3 \mathrm{R}$ " rule was proposed in that context: Rethink the concept of paid and unpaid work; Register the quantity of paid and unpaid work time; and Reallocate the unpaid work into paid one in the markets. This will surely help to design more effective policies addressing the crisis and boosting sustainable growth in the BSR ${ }^{17}$.

Despite public debate about the sustainability of development gender issues are hardly ever discussed in this context. Research shows that women live in a more sustainable way than men and that their market activity is generally more environmentally friendly. What is more, some authors claim that gender equality is a prerequisite for sustainable development ${ }^{18}$.

The International Institute for Sustainable Development related to the United Nations explore sustainability in 5 main areas: Climate Change Adaptation, Climate Change and Energy, Ecosystem Services, Finance, Freshwater Management. The relation between gender equality and sustainable development is addressed mostly for the developing countries ${ }^{19}$.

\section{Research Purpose, Thesis and Tasks}

The reference literature review has proven that there is a gap in the studies on the relationship between the development and time allocation. Therefore the aim of this article is to propose a simple Taxonomic Measure of Sustainable Development and to measure its relation with time use. A thesis has been formulated that there is a relation between the level of the sustainable development and the time allocation, particularly in terms of unpaid work.

The research follows the scheme: i) the construction of the TMSD; ii) the regression analysis of the TMSD and time allocation variables; iii) the comparative analysis of the TMSD in 2004 and 2012 and the interpretation of the results.

\section{Methodology}

The authors propose the Taxonomic Measure of Sustainable Development TMSD constructed on the basis of the Sustainable Development Indicators published by Eurostat. The TMSD has been calculated as a simple average of the variables:

where:

$$
\operatorname{TMSD}_{i}=\frac{\sum_{j=1}^{10} X_{i j}}{10}
$$

$T M S D_{i}$ - Taxonomic Measure of Sustainable Development in the $i$ th country,

$X_{i j}-$ the $i$ th value $j$ th Sustainable Development variable. 
The TMSD for each country has been defined as the value ranging from 0 to 1 , where 0 means the total absence of sustainability in the country and 1 means a totally sustainably developed country when it comes to the analyzed variables. The variables have been normalised to range from 0 to 1 , and expressed as stimulants.

In the further steps of the analysis the relation between the TMSD and the time use variables was measured by means of the multivariate linear regression model ${ }^{20}$ :

$$
\hat{Y}_{i}=\beta_{o}+\beta_{1} Z_{1 i}+\beta_{2} Z_{2 i}+\beta_{3} Z_{3 i}+\ldots+\beta_{k} Z_{k i}
$$

where:

$\hat{Y}_{i}-$ the $i$ th value of the dependent variable,

$Z_{k i}-$ the $i$ th value of the $k$ th independent variable,

$\beta_{0}, \beta_{1}, \ldots, \beta_{k},-$ the regression coefficients.

In order to assess the overall fit of the estimated model the following measures were determined:

$R^{2}$ - the coefficient of determination that measures the percentage of the variation of the $\hat{Y}$ explained by the variation of the independent variables $Z$,

$R^{2}$ adj. - the coefficient of determination adjusted for the degrees of freedom,

$\mathrm{Se}-$ standard errors of the coefficients,

$t$ - values indicating the significance of the coefficients,

$p-$ the probability.

\section{Data}

The empirical analysis has been performed on the basis of the Sustainable Development Indicators which are used to monitor the EU Sustainable Development Strategy in a report announced by Eurostat every two years. They are presented in ten themes: socio-economic development, sustainable consumption and production, social inclusion, demographic changes, public health, climate change and energy, sustainable transport, natural resources, global partnership and, finally, good governance. The measure is very simple. The authors do not use any wages, presuming equal influence of each of the component variables.

Out of more than 100 indicators, twelve have been identified as headline indicators. They are intended to give an overall picture of whether the European Union has achieved progress towards sustainable development in terms of the objectives and targets defined in the strategy. 
The variables which are used in this research to calculate TMSD are:

$X_{1}$ - Growth rate of real GDP per capita,

$X_{2}$ - Resource productivity,

$X_{3}$ - People at-risk-of-poverty or social exclusion,

$X_{4}$ - Employment rate of older workers,

$X_{5}$ - Healthy life years and life expectancy at birth,

$X_{6}$ - Greenhouse gas emissions,

$X_{7}$ - Share of renewable energy in gross final energy consumption,

$X_{8}$ - Primary energy consumption,

$X_{9}$ - Energy consumption of transport relative to GDP,

$X_{10}$ - Official development assistance as share of gross national income.

Two of the monitored headline indicators: the Common Bird Index and the Fish Catches are omitted in the study as there is no data available for the years of this observation.

The time use data come from the Harmonised European Time Use Survey (HETUS) conducted by Eurostat. The three main time allocation variables have been chosen for the purpose of this study:

$Z_{1}$ - Paid work time in minutes daily,

$Z_{2}$ - Unpaid work time in minutes daily,

$Z_{3}$ - Free time in minutes daily.

The analysis of the sustainability of development has been performed for nine Baltic Sea Region countries: Denmark, Estonia, Finland, Germany, Latvia, Lithuania, Norway, Poland and Sweden. The data concern the years 2004 and 2012.

The regression between TMSD and time allocation variable was accomplished for eight countries $^{21}$.

\section{Empirical Analysis of the Relation between Sustainable Development and Time Allocation}

In this part the values of the TMSD for the BSR countries are presented. The calculations have been made basing on the equation 1. TMSD has been determined for two periods: 2004 and 2012. The strength of the relation between the TMSD and time allocation variables is measured by means of the linear regression model - equation 2 .

In 2004 the TMSD differed substantially across the BSR countries (Figure1). The countries with the lowest level of sustainable development were Poland and Germany followed 
immediately by lower income countries such as Estonia, Latvia and Lithuania. The best situation in terms of the examined variables was observed in Norway, Denmark, Finland and Sweden.

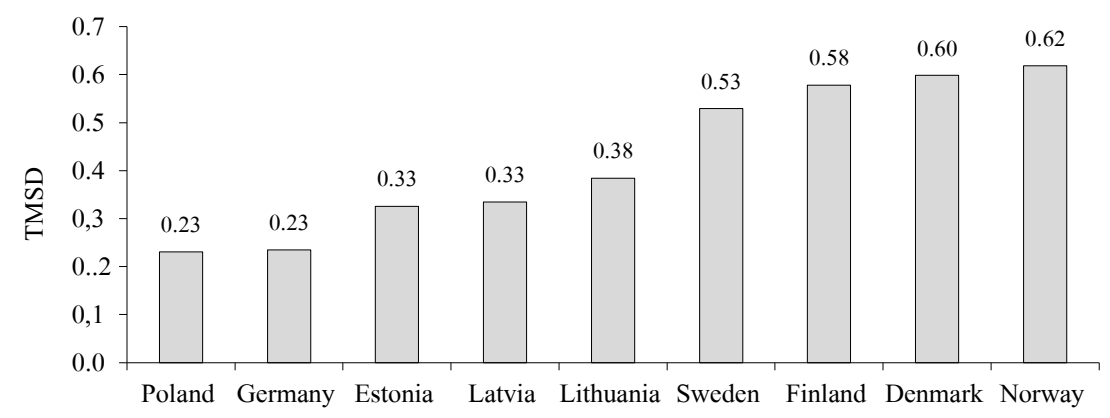

Fig. 1. Taxonomic Measure of Sustainable Development in the BSR countries in 2004 Source: own study on the basis of the UNDP and the Eurostat data.

Surprisingly low value of the German index is a consequence of its poorly assessed socioeconomic development - in this instance measured with the growth rate of real GDP per capita, relatively poorly rated demographic changes as well as unfavourable parameters of climate change and energy. In the case of the latter, Germany witnessed particularly large primary energy consumption.

Another step in this analysis is the measurement of how strong the relationship is between the sustainable development and time use.

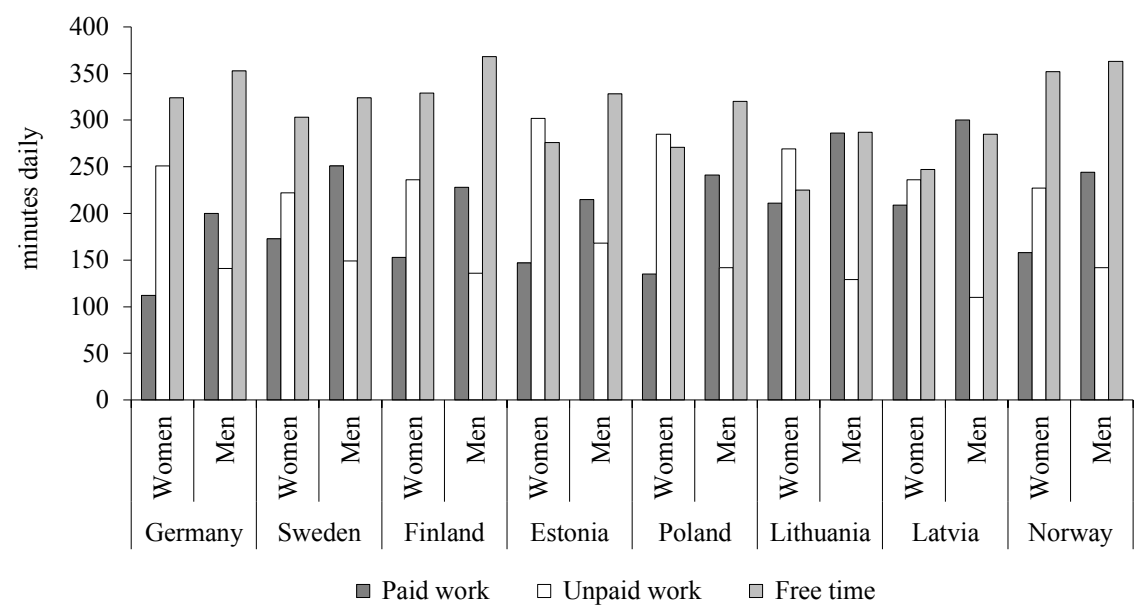

Fig. 2. Time Use in BSR countries in 2004

Source: own study on the basis of the Eurostat data. 
Time use budgets show that in all the countries, both less developed like Poland and more developed like Sweden, women spend considerably less time at paid work than men and more time doing unpaid work. What is more, they have less free time than men. The term of paid work is understood here as all the activities related to market work, including travelling to work. Unpaid work means household work and duties performed on behalf of third parties. This group includes almost 50 activities, such as child care, elderly care, cooking meals, getting clothes ready, cleaning and animal care.

The estimated regression models of TMSD and time use are presented as the equations 3-5. The models were calculated separately for the main time use structure components which are paid work, unpaid work and free time. The equation below shows the model for the paid work:

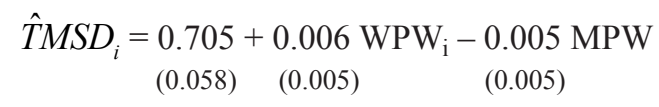

where:

$\hat{T} M S D_{i}-$ the Taxonomic Measure of Sustainable Development in the $i$ th country,

$W P W_{i}$ - the Women's Paid Work Time in the $i$ th country,

$M P W_{i}$ - the Men's Paid Work Time in the $i$ th country.

Table 1. Regression between the Taxonomic Measure of Sustainable Development and the paid work by gender

\begin{tabular}{|l|c|c|c|c|l|}
\cline { 2 - 5 } \multicolumn{1}{c|}{} & $\beta_{k}$ & St. Err. & $t$ & $p$ & \multirow{2}{*}{$R^{2}=0.20$} \\
\hline WPW & 0.006 & 0.005 & 1.107 & 0.317 & $\Phi^{2}=0.80$ \\
MPW & -0.005 & 0.005 & -0.952 & 0.384 & Se $=0.16$ \\
\cline { 1 - 4 } Intercept & 0.705 & 0.578 & 1.216 & 0.278 & $N=8$ \\
\hline
\end{tabular}

Source: own study on the basis of the Eurostat data.

Despite the fact that the quality of the model is low and none of the structural coefficients is statistically significant, it is worth mentioning that the sign at men's paid work time coefficient is negative, and the sign at women's paid work time is positive. It encourages the supposition that the more women's paid work, the more sustainably developed the economy. The determination coefficient was at the low level 0.20. The mean differences between empirical and theoretical values were $0.16(\mathrm{Se})$. 
The next model describing the relation between the level of sustainability of economies and the unpaid work time demonstrated a higher quality and a better fit. The details are shown in the equation 4 :

where:

$$
\begin{aligned}
\hat{T M S D_{i}=} & 1.008-0.004 \mathrm{WUW}_{\mathrm{i}}+0.004 \mathrm{MUW} \\
& (0.449) \quad(0.002)
\end{aligned}
$$

$\hat{T} M S D_{i}$ - the Taxonomic Measure of Sustainable Development in the $i$ th country,

$W U W_{i}$ - the Women's Unpaid Work Time in the $i$ th country,

$M U W_{i}$ - the Men's Unpaid Work Time in the $i$ th country.

Table 2. Regression between the Taxonomic Measure of Sustainable Development and the unpaid work by gender

\begin{tabular}{|l|c|c|c|c|l|}
\cline { 2 - 5 } \multicolumn{1}{c|}{} & $\beta_{k}$ & St. Err. & $t$ & $p$ & \multirow{2}{*}{$R^{2}=0.58$} \\
\hline WUW & -0.004 & 0.002 & -2.608 & 0.048 & $\Phi^{2}=0.42$ \\
\cline { 1 - 4 } MUW & 0.004 & 0.003 & 1.253 & 0.266 & $S e=0.12$ \\
\cline { 1 - 4 } Intercept & 1.008 & 0.445 & 2.246 & 0.075 & $N=8$ \\
\hline
\end{tabular}

Source: own study on the basis of the Eurostat data.

It the above model two significant structural coefficients can be distinguished - the one at the women's unpaid work time as well as at the intercept. The determination coefficient $R^{2}$ was 0.58 and was the highest compared to the other two models, the former and the successive one. The negative sign of the relation between the women's unpaid work time and the sustainability of development shows that in the countries where women are not primarily assigned as household workers the level of sustainability is higher e.g. in the Scandinavian countries. It should be mentioned that women have been doing unpaid household chores for millennia and nowadays their engagement in the labour market and paid work determines the level of their country's growth.

The relation between TMSD and the third time allocation variable - the free time of women and men in the BSR countries is shown by the equation 5:

where:

$$
\hat{T M S D} D_{i}=0.237+0.004 \mathrm{WFT}_{\mathrm{i}}-0.003 \mathrm{MFT}
$$

$\hat{T} M S D_{i}$ - the Taxonomic Measure of Sustainable Development in the $i$ th country,

$W F T_{i}$ - the Women's Free Time in the $i$ th country,

$M F T_{i}$ - the Men's Free Time in the $i$ th country. 
Table 3. Regression between the Taxonomic Measure of Sustainable Development and the free time by gender

\begin{tabular}{|l|c|c|c|c|l|}
\cline { 2 - 5 } \multicolumn{1}{c|}{} & $\beta_{k}$ & St. Err. & $t$ & $p$ & \multirow{2}{*}{$R^{2}=0.31$} \\
\hline WFT & 0.004 & 0.004 & 0.952 & 0.384 & $\Phi^{2}=0.69$ \\
\cline { 1 - 4 } MFT & -0.003 & 0.006 & -0.522 & 0.624 & $S e=0.15$ \\
Intercept & 0.237 & 0.804 & 0.295 & 0.780 & $N=8$ \\
\hline
\end{tabular}

Source: own study on the basis of the Eurostat data.

The quality of the model is not satisfying at all. None of the coefficients is significant, and the fit of the models is low, too. On the basis of the results it can be concluded that a thesis that there is a significant relation between the level of sustainable development and the time allocation, particularly in terms of unpaid work, cannot be confirmed. It can still be seen that the shorter the time of women's unpaid household work, the more sustainably developed the economy, but this relation surely needs some further research which should be executed on the basis of the wider number of observations. It can be done through adding new countries to the analysis or extending the observation over more periods of time.

\section{Evident Changes in the Level of Sustainable Development}

So far the TMSD has been calculated for 2004 because that was the year when the Time Use Survey for all the BSR was last conducted ${ }^{22}$. The last step in this study is to calculate the TMSD for 2012 and to compare the results for both years (Table 4). The analysis was made with the use of the same normalisation parameters.

Table 4. Comparative Analysis of the Taxonomic Measure of Sustainable Development in 2004 and 2012

\begin{tabular}{|l|c|c|c|}
\hline \multicolumn{1}{|c|}{ Country } & TMSD 2004 & TMSD 2012 & Change \\
\hline Poland & 0.23 & 0.24 & 0.01 \\
\hline Germany & 0.23 & 0.37 & 0.14 \\
\hline Estonia & 0.33 & 0.42 & 0.10 \\
\hline Latvia & 0.33 & 0.32 & -0.02 \\
\hline Lithuania & 0.38 & 0.39 & 0.01 \\
\hline Sweden & 0.53 & 0.59 & 0.06 \\
\hline Finland & 0.58 & 0.45 & -0.13 \\
\hline Denmark & 0.60 & 0.45 & -0.14 \\
\hline Norway & 0.62 & 0.73 & 0.11 \\
\hline
\end{tabular}

Source: own study on the basis of the Eurostat data. 
In the period of study the changes in the sustainable development level measured with Eurostat Headline Indicators were clearly visible. In the majority of the BSR countries (6 out of 9) the increase in TMSD was observed. Three countries (Denmark, Finland and Latvia) saw the TMSD decrease. The situation in Germany improved, which can be proved by the highest positive change in the group. What is more, the ranking order in 2012 was different in comparison to 2004 .

Ranking 2004: 1. Norway, 2. Denmark, 3. Finland, 4. Sweden, 5. Lithuania, 6. Latvia, 7. Estonia, 8. Germany, 9. Poland.

Ranking 2012: 1. Norway, 2. Sweden, 3. Denmark, 4. Finland, 5. Estonia, 6. Lithuania, 7. Germany, 8. Latvia, 9. Poland.

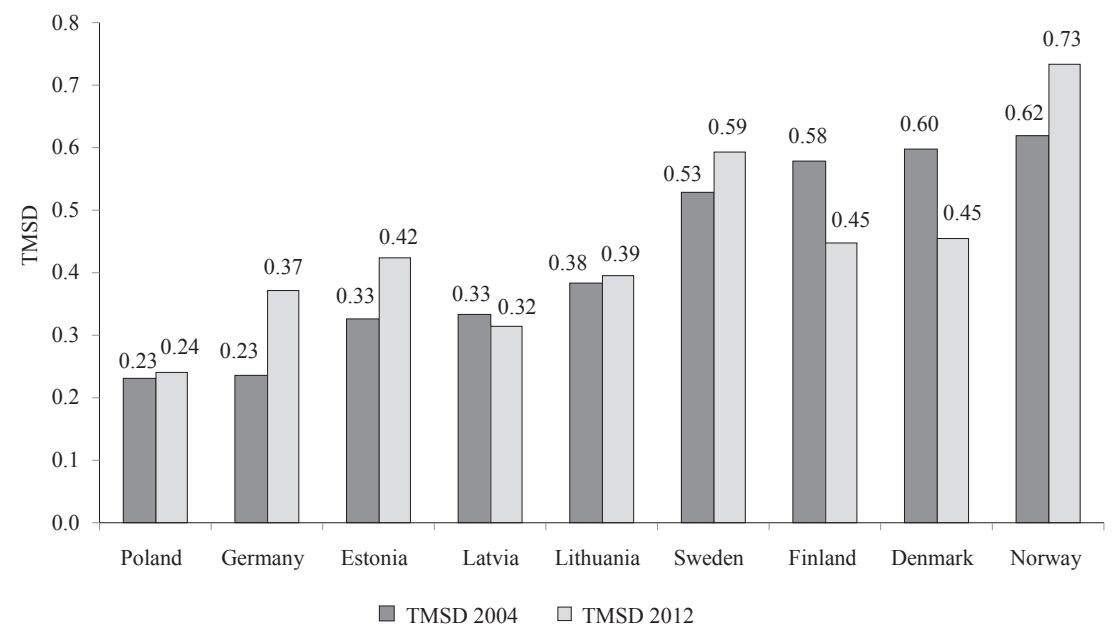

Fig. 3. Taxonomic Measures of Sustainable Development in 2004 and 2012 in BSR countries Source: own study on the basis of the Eurostat data.

Beside the one-way changes in TMSD (upward tendency in most countries), in both analysed years the observed countries can be divided into two groups: the well-off and better developed Scandinavian countries with Norway and the group of less developed countries that had undergone economic transformation (Figure 3). The latter have been catching up with the more developed states from the first group, but many differences in the micro-economic, social and environmental spheres can still be observed. It is strongly related to the economic convergence theory. J. Batóg and B. Batóg (2006) made an analysis of the Convergence in BSR Region using advanced quantitative methods. 


\section{Conclusions}

The Taxonomic Measure of Sustainable Development and the measurement of its relation with the men's and women's time allocation is a response to the recommendation by "Sarkozy's Commission" (Commission on the Measurement of Economic Performance and Social Progress) to include non market phenomena in economic analyses. Therefore the measure of Sustainable Development has been proposed and its relation with the time allocation has been measured in this article.

The TMSD illustrates well how strongly differentiated the BSR countries are in terms of sustainable development. The best situation was observed in the Scandinavian countries and Norway. In the majority of the countries the level of development rose over the time of observation.

The thesis about the relation between the level of sustainable development and the time allocation have not been proved. In further studies the authors plan to cover in a similar analysis a larger number of European countries, preferably the whole EU-27, as well as to use other functional forms of the regression model of the relation between the TMSD and time use variables.

\section{Notes}

${ }^{1}$ Johnsson-Latham (2007).

${ }^{2}$ Lofstrom (2009); Klasen, Lemanna (2009).

3 OCED (2008).

${ }^{4}$ Stiglitz et al. (2010).

5 Stocky (2006).

${ }^{6}$ Boserup (1970); Beneria (1995) and Antonopoulos, Hirway (2010).

${ }^{7}$ Seguino et al. (2009).

${ }^{8}$ Hozer (2004).

${ }^{9}$ Stiglitz et al. (2010).

${ }^{10}$ Lis (2010).

11 Izdes (2007).

12 Seguino et al. (2009).

${ }^{13}$ Rumińska-Zimny (2009); see also Lofstrom (2009); Smith, Bettio (2008); World Economic Forum (2012).

14 Antonopoulos, Hirway (2010); Esquivel et al. (2008).

15 OECD (2008); Stiglitz et al. (2010).

16 OECD (2008).

${ }^{17}$ Hozer-Koćmiel (2010).

18 Johnsson-Latham (2007). 
${ }^{19}$ Kiratu, Roy (2010); Chandra et al. (2010); Ventura-Dias (2010).

${ }^{20}$ Hozer (2005).

${ }^{21}$ There is no suitable data for Denmark in HETUS Survey.

${ }^{22}$ In collaboration with Eurostat National Statistical Offices have been preparing the next edition of the survey covering the period of 2012-2014. However, data about some countries have not been made available yet.

\section{References}

Antonopoulos, R. \& Hirway, I. (2010). Unpaid Work and the Economy. Gender, Time Use and Poverty in Developing Countries. Palgrave Macmillan.

Batóg, B. \& Batóg, J. (2006). Analysis of Income Convergence in the Baltic Sea Region. "Baltic Buisiness Development: Regional development SME management and entrepreneurship". Szczecin: University of Szczecin.

Beneria, L. (1995). Toward Greater Integration of Gender in Economics. Cornell University.

Boserup, E. (1970). Women's Role in Economic Development. George Allen and Unwin.

Chandra, A., Lontoh, L. \& Margawati A. (2010). The Gender Implications of Trade Liberalization in Southeast Asia. Beyond Barriers, The International Institute for Sustainable Development, Winnipeg, Manitoba Canada.

Eurostat - Harmonised European Time Use Survey, www.h2.scb.se/tus/tus.

Esquivel, V., Budlender, D., Folbre, N. \& Hirway, I. (2008). Explorations: Time Use Surveys in the South. Feminist Economics, July, 107-152.

Hozer, J. (2004). Matematyczno-ekonomiczne modele funkcjonowania gospodarki. Szczecin: Wydawnictwo Naukowe Uniwersytetu Szczecińskiego.

Hozer, J. (2005). Ekonometria. Szczecin: Wydawnictwo Naukowe Uniwersytetu Szczecińskiego.

Hozer-Koćmiel, M. \& Zimoch, U. (2010). Statistical Portrait of Women in ICT in BSR countries, Report Baltic Sea Region Conference with focus on Gender ICT. Winnet Sverige.

Izdes, O. (2007). Financial Crises of Turkey and Gendered Employment Outcomes, https:// editorialexpress.com/cgi-bin/conference/download.cgi?db_name=IAFFE2010\&paper_ $\mathrm{id}=292$.

Johnsson-Latham, G. (2007). A study on gender equality as a prerequisite for sustainable development. Report to the Environment Advisory Council, Sweden.

Kiratu, S. \& Roy, S. (2010). The Gender Implications of Trade Liberalization in Southern Africa. Beyond Barriers, The International Institute for Sustainable Development, Winnipeg, Manitoba Canada.

Klasen, S. \& Lamanna, F. (2009). The Impact of Gender Inequality in Education and Employment on Economic Growth: New Evidence for a Panel of Countries. Feminist Economics, 15 (3).

Lis, C. (2010). Modelowanie predyktywne wartości dodanej brutto w Polsce. Szczecin: CBE. 
Lofstrom, A. (2009). Gender equality, economic growth and employment. Swedish Ministry of Integration and Gender Equality, www.arifl.regione.lombardia.it/shared/ccurl/278/82/ EUstudie_sidvis[1].pdf.

OECD (2008). Glossary of Statistical Terms, http://stats.oecd.org/glossary.

Picchio, A. (2003). Unpaid work and the economy: a gender analysis of the standards of living. New York: Routledge.

Rumińska-Zimny, E. (2009). Gender Gap and Economic Policy, UNECE, www.unece.org/gender/publications.

Seguino, S., Berik, G. \& Rodgers, Y. (2009). Promoting Gender Equality as a means to Finance Development. Friedrich Ebert Stiftung, www.uvm.edu/ sseguino/pdf/Gender_equality_financing_for_development.pdf.

Smith, M. \& Bettio, F. (2008). Analysis Note: The Economic Case for Gender Equality. European Commission, DG Employment, Social Affairs and Equal Opportunities.

Stigliz, J.E, Sen, A. \& Fitoussi, J.P. (2010). Report by the Commission on the Measurement of Economic Performance and Social Progress, www.stiglitz-sen-fitoussi.fr.

Stocky, J.G. (2006). Gender and Its Relevance to Macroeconomic Policy: A Survey. Working Paper WP/06/233, International Monetary Fund.

Ventura-Dias, V. (2010). The Gender Implications of Trade Liberalization in Latin America. Beyond Barriers, The International Institute for Sustainable Development, Winnipeg, Manitoba Canada.

World Economic Forum (2012). The Global Gender Gap Report, www3.weforum.org/docs/ WEF_GenderGap_Report_2012.pdf.

Zammit, A., Berik, G. \& Rogers, Y. (2009). Social Justice and Gender Equality: Rethinking Development and Macroeconomic Policies. Routledge/UNRISD Research in Gender and Development. 